ISSN: 1130-3743 - e-ISSN: 2386-5660

DOI: http://dx.doi.org/10.14201/teoredu3012951

\title{
ESCENARIOS Y RAZONES DEL ANTIPEDAGOGISMO ACTUAL $^{1}$
}

\section{Circumstances and reasons for the current anti-pedagogism}

\section{Contextes et raisons de l'antipédagogisme actuel}

\author{
Fernando GIL CANTERO \\ Universidad Complutense de Madrid. Facultad de Educación. \\ Centro de Formación del Profesorado. Calle Rector Royo Villanova, 1. 28040 Madrid. \\ gcantero@edu.ucm.es
}

Fecha de recepción: enero de 2018

Fecha de aceptación: marzo de 2018

RESUMEN

El objetivo de este artículo estriba en analizar algunas de las razones del desprestigio actual del conocimiento pedagógico. En primer lugar, se muestran algunos ejemplos nacionales e internacionales sobre el ambiente cultural de rechazo hacia la Pedagogía y los pedagogos. En segundo lugar, se presenta una revisión de las principales posiciones en juego sobre el antipedagogismo. En tercer lugar, se analizan algunas de las razones que pueden explicar la actual corriente antipedagógica. Estas razones se basan en posibles errores o excesos de cierta Pedagogía. Razones políticas centradas en la excesiva polarización ideológica entre escuela tradicional y progresista o nueva. Razones gnoseológicas centradas en separar en exceso la perspectiva

1. Este artículo se realiza en el marco del proyecto de investigación La iniciación en el desarrollo profesional docente en la educación obligatoria: de las políticas supranacionales a las trayectorias profesionales (EDU2015-65743-P, IP: J. M. Valle) y es parte de la lección de acceso a Cátedra del autor en la Universidad Complutense de Madrid, dictada el 22 de marzo de 2018. Agradezco al tribunal evaluador sus sugerencias: F. Bárcena, M. ${ }^{a}$ R. Buxarrais, Á. García Del Dujo, J. Trilla y G. Ossenbach. 
educativa y el aprendizaje de las áreas culturales. Y, por último, razones normativas centradas en identificar la educación con la vida y las experiencias subjetivas.

Palabras clave: antipedagogismo; conocimiento pedagógico; normatividad.

\section{SUMMARY}

The aim of this article is to analyze some of the reasons for the current discrediting of pedagogical knowledge. First, some national and international examples of the cultural circumstances for the rejection of Pedagogy as an academic discipline and pedagogues as valid professionals are established. Secondly, a review of the main positions at stake on anti-pedagogism is presented. Thirdly, some of the reasons that may explain the current anti-pedagogim are analyzed. These reasons are based on possible mistakes or excesses of a certain kind of Pedagogy. There are political reasons; Pedagogy has allowed an excessive ideological polarization between traditional schools and progressive or new schools. There are gnoseological reasons as well; Pedagogy has separated way too much the educational perspective and the learning from the cultural content in the curriculum areas. And, finally, there are normative reasons too; Pedagogy has focused excessively on identifying education with life and subjective experiences.

Key words: anti-pedagogism; pedagogical knowledge; normativity.

\section{SOMMAIRE}

L'objectif de cet article est d'analyser certaines des raisons du discrédit actuel des connaissances pédagogiques. Tout d'abord, quelques exemples nationaux et internationaux du contexte culturel du rejet de la pédagogie en tant que discipline académique et des pédagogues en tant que professionnels valides sont présentés. Deuxièmement, une révision des principales positions de l'antipédagogisme est réalisée. Troisièmement, certaines des raisons qui expliquent le courant anti-pédagogique sont analysées. Ce sont des raisons fondées sur des possibles erreurs ou excès d'une certaine Pédagogie. Il y a des raisons politiques: la Pédagogie a favorisé une excessive polarisation idéologique entre les écoles traditionnelles et les écoles progressistes ou nouvelles. Il y a des raisons gnoséologiques: la Pédagogie a trop séparé la perspective éducative et de l'apprentissage du contenu culturel dans les domaines du curriculum. Et, il y a enfin, des raisons normatives: la Pédagogie a excessivement identifié l'éducation avec la vie et les expériences subjectives.

Mots clés: antipedagogisme; connaissances pédagogiques; normativité. 


\section{INTRODUCCIÓN}

El objetivo de este artículo estriba en analizar algunas de las razones del desprestigio actual del conocimiento pedagógico. Nuestra finalidad no es, en este caso, hacer un análisis científico de la función del saber pedagógico ni, por tanto, de su utilidad. Esta defensa ya se ha hecho desde posiciones epistemológicas relevantes y actuales en las ciencias sociales y, a nuestro modo de ver, muy clarificadoras y casi definitivas (Touriñán, 2014, 2015; Thoilliez, 2015; Ballester y Colom, 2012; Oancea y Pring, 2008; Trilla, 2005; García Carrasco y García Del Dujo, 2001; García Carrasco, 1983). Consideramos, sin embargo, que esta perspectiva, siendo imprescindible, no es suficiente para comprender las razones de las críticas contra la Pedagogía. Y no lo es porque la mayoría de estas poco o nada tienen que ver con un debate epistemológico. Esto es, no hay hoy, de un modo dominante, un enfrentamiento entre diversas posiciones acerca del grado de cientificidad de la Pedagogía. La discusión se centra, por el contrario, en destacar más la inutilidad, en general, del saber pedagógico que en cuestionar una forma concreta de entenderlo. No estamos, por tanto, ante un debate interno entre pedagogos sobre la Pedagogía, sino externo entre antipedagogos contra la Pedagogía. En definitiva, lo que se ha dado en llamar, en el contexto internacional, la corriente antipedagógica, una extensa crítica cultural contra la Pedagogía reflejada, además, como vamos a mostrar, en gran parte del imaginario colectivo de nuestra sociedad.

\section{ESCENARIO CULTURAL}

Estas críticas adoptan diversos grados. Por un lado, están las habituales que se limitan a señalar la escasa utilidad del saber pedagógico en su función de apoyo a la docencia y, por tanto, en la formación del profesorado, especialmente, de secundaria. Por otro, nos encontramos, cada vez más, con un conjunto de críticas que no se limitan a cuestionar el alcance de la utilidad de alguna función concreta de la Pedagogía, sino que cuestionan el sentido general de esta llegando, en ocasiones, a posiciones literalmente de desprecio, ensañamiento e insulto como si el saber pedagógico fuera en sí mismo dañino².

Empecemos con algunos ejemplos ligeros. Desde la creación artística, en este caso musical, nos encontramos con la siguiente canción, muy famosa, con letra de uno de nuestros poetas más reconocidos, Luis Alberto de Cuenca, e interpretada por Loquillo, que dice así en su estribillo: "Sé buena, anda, dime cosas incorrectas desde el punto de vista político... por ejemplo, que disfrutas pegando a un

2. En una reunión a la que asistí en mi facultad sobre el diseño de los dobles grados de Pedagogía y Magisterio, tuve que intervenir para aclarar que la materia de Teoría de la educación no tiene por qué perjudicar, todo lo contrario, a la formación de los maestros. Insisto: no se estaba discutiendo su mayor o menor utilidad, se argumentaba que no era conveniente para su formación, en concreto, para poder emprender innovaciones prácticas. 
pedagogo" (Loquillo, 2011). Desde el periodismo tenemos infinitas alusiones de este tipo o parecidas: "Ahora, ¿Qué hay? Ahora hay maestros y pedagogos... pocos maestros y muchos pedagogos y así nos va» (Jiménez Losantos, 2014).

Pasemos a otros ejemplos de más calado. Desde la crítica cultural y el ensayo filosófico, Steiner y Ladjali consideran que «Echémosle la culpa a Goethe, quien dijo aquello de que "quién sabe cómo hacer algo, lo hace; quien no lo sabe, se dedica a la enseñanza". Y añado por mi cuenta: "quien no sabe enseñar se dedica a escribir manuales de pedagogía”» $(2015,115)$.

No nos faltan tampoco escritores de nuestro país muy reconocidos, algunos académicos y hasta un serio candidato al Nobel, para quienes la descalificación de la Pedagogía y los pedagogos es un entretenimiento habitual: "Pedagogos charlatanes» (Prada 2017); "Los pedagogos cantamañanas» (Pérez Reverte); «El mayor éxito de los pedagogos en los últimos treinta años ha sido despojar a varias generaciones de las herramientas intelectuales para comprender racionalmente el mundo" (Muñoz Molina, 1997); «El daño que los pedagogos han hecho a la enseñanza es indescriptible» (Marías, 2016).

En Francia se encuentran en la misma situación. En un artículo de 2017 de Chambat, dedicado a reseñar los 105 libros antipedagógicos escritos en Francia desde 1978 a 2016, señala que la literatura antipedagógica es ya un "fenómeno editorial» alimentado en más de un $62 \%$ por filósofos, periodistas y políticos. Pero no cabe duda de que el debate actual con mayor resonancia pública, de más largo recorrido, agrio en ocasiones y, lamentablemente, sin gran altura académica, es el mantenido por Finkielkraut (1991, 2002, 2014) y Meirieu (2000). El primero considera que la Pedagogía nos ha hecho pasar "de una escuela sustancial a una escuela procesal. La primera propone un modelo de humanidad y sancionaba todo desvío o toda disonancia [...] la segunda deja dispersarse el concepto de humanidad [...] para que ninguna (idea de humanidad) humille o agreda a las otras, o entorpezca su libertad» (2002, 69-70; cursiva en el original). Este filósofo ya opinaba en 1991 que "las "ciencias de la educación" son de hecho técnicas de reeducación [...] "para" normalizar maestros y hacer que se avergüencen de querer ser cualquier cosa menos animadores sociales» (citado en Khan, 2006, 90).

Por último, me gustaría señalar, como expresión del ambiente cultural de rechazo descrito hasta ahora, que el desprecio hacia la Pedagogía y los pedagogos está tomando ya forma en algunos programas de partidos políticos con amplia representación parlamentaria, en concreto Ciudadanos y Podemos. Por ejemplo, en el llamado Manifiesto de Maestros y Profesores de 2010, adoptado en su momento por Ciudadanos, se propone que se «limite las atribuciones de psicólogos y pedagogos, tanto en la administración como en los centros, a los fines estrictos de su adscripción» (punto 2). Por otra parte, Fernández Liria (2015), al tratar de explicar en qué debe consistir el programa de educación de Podemos, advierte a los suyos de que "todo empezó a ser fiscalizado por estos nuevos expertos, algunos con el título de pedagogos y otros -los más- disfrazados de pedagogos, porque, al fin y al cabo, no hay nada más fácil que disfrazarse de una cosa que no existe». Así, termina 
su propuesta planteando 14 medidas para el programa político de educación de Podemos siendo la octava: "Ni rastro de pedagogos".

\section{ESCENARIO ACADÉMICO}

Para ejemplificar el proceso de desprestigio de la Pedagogía y los pedagogos, cuenta Kahn que la segunda traducción oficial al francés del Tratado de Pedagogía de Kant apareció en 1966 con el título Reflexiones sobre la educación. "Todo sucede como si ochenta años después [...] la Pedagogía fuese un tipo de discurso suficientemente deslegitimado intelectualmente como para no confundirse con el sostenido por Kant» (Kahn, 2006, 83).

Probablemente, el trabajo internacional de análisis más relevante sobre la corriente antipedagógica sea el de Forestier con un metaestudio en el que ha sometido a un escrutinio estadístico a 1.123 artículos publicados en la prensa francesa nacional de información general -donde este debate es más virulento- entre 1959 y 2008. Pues bien, los rasgos más característicos de la corriente antipedagógica resultan ser, entre otros, los siguientes: que hay una prevalencia de la misma en momentos de tensión política, profesional o social; que a lo largo de los 50 años analizados se ha pasado de centrar la crítica en la secundaria o en el bachiller a la primaria y la universidad; que cada vez se suman más intelectuales de todas las tendencias políticas; que todo lo que juzgan negativo de la Pedagogía tiene su origen tanto en algún momento histórico que consideran apocalíptico -una ley, una reforma curricular, etc.- como en la figura concreta de ciertos pedagogos, profesores o responsables políticos; que el modelo de comparación crítica no es nunca la propuesta de un proyecto mejor para el futuro, sino la reivindicación de una escuela del pasado, siempre desde una especie de "mito de una edad de oro» y, por último, que esa escuela del pasado no tiene nunca ninguna responsabilidad en los problemas actuales de la educación (Forestier, 2017, 86-87, 89-90).

Décell (2017a) propone, por su parte y con cierta gracia, aunque sin un estudio exhaustivo como el señalado, 10 «ventajas» características del antipedagogismo: 1) Adaptabilidad de $360^{\circ}$ a todas las opciones políticas; 2) La facilidad de asimilación, independientemente del conocimiento de la educación; 3) La rebeldía sin riesgo o cómo ser el Che Guevara cada mañana; 4) El derecho a la exageración; 5) La autoexoneración de toda responsabilidad; 6) Disfrute retórico; 7) Espíritu de superioridad; 8) La abolición de la contradicción (es inútil investigar, coleccionar anécdotas es suficiente); 9) La solidaridad inquebrantable entre los antipedagogos, y 10) Eternidad conceptual (una forma de pensar que siempre ha existido).

Estos rasgos coinciden bastante con los analizados, en nuestro contexto, por Prats $(2015,146-147)$ en lo que denomina «Pedagogía amarilla»: voluntad iluminista; teorías conspirativas; absolutismo teórico, esto es, solo hay una manera de entender qué es la buena educación; simplismo; apelación al sentido común y crítica a la metodología y al lenguaje pedagógico; propuestas populistas y descalificación. Por su parte, Herrán (2012, 22-25) considera que la sociedad percibe al pedagogo 
como un intruso pues el problema de la educación pertenece a todos. Trilla (2009, 227) añade también, en su caso, la relación entre la mala imagen de la Pedagogía con la degradación y dispersión del grado de Pedagogía.

Podemos, pues, considerar con Kahn $(2006,83)$ que «el antipedagogismo es la negación de cualquier valor teórico y práctico de la idea de que puede haber un contenido limpio, objetivo, coherente y enseñable en los discursos sobre las formas de enseñar, y en consecuencia, el rechazo de cualquier discurso constituido que tome estas formas de enseñanza como su objeto». Y matiza después: «El antipedagogismo no niega la importancia que la relación pedagógica establecida por el maestro con su clase o clases puede tener para el éxito de su enseñanza; pero rechaza el hecho de que uno puede enunciar en general y en abstracto las condiciones de esta relación» (Ídem).

La última referencia que me gustaría señalar es un debate que ha enfrentado al profesor Santos Guerra en su blog con los representantes más conocidos del antipedagogismo. Me interesa esta discusión no solo por la fecha en la que se realiza -octubre de 2017-, sino por el lamentable escaso nivel académico, la agresividad y la falta de respeto a la que se llegó por parte de otros. Por ejemplo, Moreno Castillo planteó en sucesivas entradas, y como respuesta a otras tantas de Santos, los siguientes comentarios: "La pedagogía no me merece más respeto que (la) adivinación y la cartomancia [...] en cuanto a las clases que recibí de pedagogos, no es que algunas hayan sido malas, es que en todas pasé auténtica vergüenza [...] No es que no piensen como yo (los pedagogos), es que no piensan" (en Santos Guerra, 2017). Poco antes ya le habíamos leído, en un libro subtitulado De como los pedagogos han destruido la enseñanza, que "la pedagogía es un lenguaje sin contenido, una jerga" (Moreno, 2016a, 19). En fin, cuando preguntaron a Xavier Massó (2013), presidente de la Federación Nacional de Sindicatos de Profesores de Secundaria de España, qué medidas proponía para superar el fracaso escolar sugirió taxativamente y en primer lugar «que se cierren de una vez las facultades de Pedagogía».

Podemos estar tentados de despachar todas estas cuestiones basándonos en el desvarío y exageraciones de algunos pues siempre ha habido pedagogos de fortuna y, lo peor de todo, iluminados, los que el profesor García Carrasco llamaba con buen humor "pedagogos toreros que creen haber dado con la faena de gracia al mandar autoritariamente a todos los peones que se retiren" $(1983,172)$. Pero creo que nos equivocaríamos si como investigadores de la Pedagogía no buscásemos las razones que sostienen estos rechazos. Alberto Royo, uno de los críticos más activos y conocidos, se quejó en el debate que acabamos de mencionar de que "hasta ahora no he escuchado a ningún pedagogo criticar a la pedagogía o reconocer sus errores» (en Santos Guerra, 2017). Y es que, como ha reconocido el profesor Touriñán en su imprescindible tratado de Pedagogía General, «la imagen 
social de la pedagogía no es buena: no es la que tendría que ser [...], y tampoco estamos haciendo lo que procede para cambiarla» $(2014,248)^{3}$.

Por eso, nuestro propósito es analizar las razones de este desprestigio, pero, como ya se ha indicado, no por vía epistemológica sino cultural. Y queremos hacerlo reconociendo los errores que, como pedagogos, hemos podido cometer. En efecto, cuando se analiza, sin prejuicios, la abundante bibliografía crítica contra el saber pedagógico nos encontramos, en la mayoría de los casos, con una caricatura de la Pedagogía, por eso desproporcionada y hasta ridiculizadora -que nada nos interesa contrarrestar por fatua-, pero que surge desde apreciaciones, ahora sí, acertadas sobre algunos errores, excesos o despropósitos que hemos favorecido los mismos pedagogos y, sobre todo, aunque nunca lo reconozca la literatura antipedagógica, otros profesionales cuando se ponen a hacer Pedagogía. No pretendo realizar, pues, una defensa beligerante, gremial y cerrada de la Pedagogía dado que el mejor modo de entender y reconocer las verdades de nuestros atacantes es, precisamente, reconociendo nuestros posibles errores.

Hemos agrupado así las razones principales que, a nuestro juicio, explican mejor estos errores pedagógicos en tres grandes apartados: razones políticas o ideológicas, gnoseológicas o filosóficas y normativas o éticas.

\section{RAZONES POLÍTICAS}

Una de las causas que explica la desacreditación cultural del pensamiento pedagógico es su excesiva polarización entre las llamadas pedagogía tradicional y la pedagogía progresista o nueva. Por supuesto, no estoy haciendo referencia a la diversidad legítima de teorías y, por tanto, de modos de orientar las prácticas educativas. Pero sí considero que, como pedagogos, colaboramos en el desprestigio del discurso pedagógico cuando defendemos que solo se puede hacer buena Pedagogía desde una posición ${ }^{4}$.

Como toda dicotomía está mal planteada. A la pedagogía tradicional se le atribuye, por parte de algunos, todos los males de la educación y, por parte de otros, todas las bondades. Lo mismo ocurre con la pedagogía progresista. Estamos, pues, ante una clara perspectiva maniquea, típica del antipedagogismo. En efecto, Reboul al reseñar el libro de Milner de 1984, reeditado en 2009, uno de los textos más emblemáticos de la literatura antipedagógica, reconoce en la Pedagogía un «inevitable discurso dicotómico»-aquí diríamos antinómico- pero que la corriente antipedagógica, según él, «empeora» $(1985,73)$. En realidad, estas perspectivas no

3. Para el profesor Vilanou, la situación es peor: "La Pedagogía, disciplina condenada hoy a ser residual en el mundo posmoderno" $(2015,212)$.

4. Este curso académico (2017-2018) me ha preguntado un alumno de 3 . $^{\text {er }}$ curso "si estaba a favor de la Pedagogía de siempre o de la Pedagogía transformadora». Lo que no es tan extraño cuando compañeros míos hacen gala de presentarse en la primera clase como "pedagogos progresistas" o "partidarios de la pedagogía tradicional». 
se sostienen. Ni por un lado ni por otro. La buena Pedagogía no es ni tradicional ni progresista, es buena Pedagogía a secas.

El carácter fuertemente ideologizado de este maniqueísmo pedagógico puede comprobarse en la arbitrariedad de sus propios argumentos: lo que antes se criticaba de la pedagogía tradicional pasa ahora a alabarse, y lo que se alababa de la escuela nueva pasa ahora, casi punto a punto, a criticarse. Como dice Kahn, refiriéndose al contexto cultural francés, filósofos, escritores, periodistas y políticos que a mitad del siglo pasado mantenían posiciones claramente reformadoras se han sumado ahora a la corriente antipedagógica (2006, 85). Por ejemplo, en nuestro contexto, en el libro Nos quieren más tontos. La escuela según la economía neoliberal, Carrera y Luque (2016) critican muy duramente los siguientes aspectos de la educación actual: la invasión de las nuevas tecnologías $(37,83,127)$, el constructivismo $(30,84)$, la disminución del valor del conocimiento $(52,53)$, el papel del profesor como mero entrenador o animador (149, 150), la mediocridad intelectual (150) y hasta el relativismo cultural (150). Por otro lado, defienden ahora, beligerantemente, lo que antes se criticaba de la escuela tradicional: la memoria (83), el esfuerzo intelectual (por ejemplo, afirman, «se está desarrollando otra idea especialmente peligrosa, el ludismo educativo [...] el saber ha de ser divertido y no ha de costar esfuerzo»-148-), y hasta utilizan (53) como referencia bibliográfica central el conocido texto de Arendt (1996) sobre la importancia de la tradición y de la disciplina que, como es sabido, era el mismo que usaba la literatura defensora de la escuela tradicional para atacar los resultados obtenidos por la escuela progresista. Todo esto ha llevado a Décell (2017b) a preguntarse "¿Cómo se puede mover el mismo conjunto de ideas sobre educación, con armas y equipaje, de un extremo al otro del espectro (político)?».

Otro ejemplo, también reciente y muy significativo, es el fuerte debate generado en la izquierda y en las corrientes defensoras de la escuela nueva, por la publicación del libro de Fernández Liria y otros (2017) titulado significativamente Escuela o barbarie 5 . Pues bien, Liria considera -sin ahorrar, por supuesto, todo tipo de adjetivos despreciativos contra la Pedagogía y los pedagogos- que muchas de las propuestas llevadas a cabo por los pedagogos de la escuela nueva frente a la escuela tradicional son, como reza el subtítulo del libro, un "delirio". Es un texto que podrían haber firmado los defensores más destacados de la escuela tradicional. Por ejemplo, Juan Manuel de Prada (2017) alabó abiertamente este libro y aconsejó su lectura a todo el profesorado. Por otra parte, Jaume Carbonell, defensor incansable de los planteamientos de la escuela nueva, al reseñar los dos libros indicados señala que en ellos se da «un rechazo radical y delirante [...] a la pedagogía [...] (un) conjunto de argumentos tan endebles de esta otra izquierda que en el terreno educativo y pedagógico proponen un discurso muy trasnochado y conservador» (Carbonell, 2017).

5. Por las mismas fechas se publicaba en Francia, desde la órbita de la derecha, el último libro de Bentolila, también titulado, curiosamente, La escuela contra la barbarie (2017). 
Creo que estos análisis nos permiten sacar algunas conclusiones. La primera que reducir con argumentos simplistas el pensamiento pedagógico a un planteamiento dicotómico e ideologizado entre escuela tradicional y escuela nueva termina ocultando la verdadera complejidad de la realidad educativa y, por tanto, favorece, a su vez, un ejercicio sectario y aun histérico de oposición a cualesquiera que sean las prácticas educativas presentes, abrazando y dando siempre por bueno lo contrario. El propio Dewey, al ver cómo se trabaja en algunas escuelas progresistas, se vio en la obligación de advertir que: «los problemas no son reconocidos, y mucho menos resueltos, cuando se supone que basta rechazar las ideas y prácticas de la antigua educación y pasar al extremo opuesto» $(2010,69)$.

La segunda conclusión es que si el conocimiento pedagógico solo se sostiene desde posiciones ideológicas va perdiendo credibilidad y respetabilidad como un saber estable, con ciertos niveles de certeza, pasando así a ser fácilmente vapuleado al antojo de cualquier instancia - personal, institucional, legal, periodística o partidista- y a situarse, finalmente, en los espacios culturales de más escaso reconocimiento científico como son las tertulias y los debates parlamentarios. Y ya, a partir de aquí, el ipim, pam pum, fuego! contra la Pedagogía es imparable.

Por último, como ha señalado el profesor Ibáñez-Martín (2017, 15 y ss.), «el sistema educativo ya no puede continuar diseñándose para promover la ideología de quienes tienen el poder, sino que tiene ante sí responsabilidades mucho más profundas".

Frente a la ideologización de la educación no me preocupa, en realidad, que el antipedagogismo quiera desprestigiar a la Pedagogía y a los pedagogos. Tampoco le doy mucha importancia a los frecuentes insultos, si bien resultan culturalmente significativos. Lo que realmente me inquieta es que bajo toda esta politización y sus constantes vaivenes y maniqueísmos argumentales quieran debilitar la posibilidad de alcanzar algún conocimiento estable sobre la educación. Y creo que esto es, precisamente, lo que se busca: que la educación y con ello la Pedagogía pasen a ser lo que a cada uno le apetezca pues ya sin principios pedagógicos, sin un suelo estable, caben todo tipo de afirmaciones teóricas, y sus contrarias; caben todo tipo de supuestas innovaciones prácticas y sus opuestas; caben, en fin, metodologías insignificantes, visiones fragmentarias y exageraciones críticas e incluso -y este es, en ocasiones, uno de los rasgos más sorprendentes de cierto pensamiento pedagógico- caben todas al mismo tiempo.

Para terminar este apartado nos queda por responder una pregunta. ¿Como pedagogos e investigadores de la educación qué podemos hacer para no favorecer la ideologización de la educación y, por tanto, ciertos discursos antipedagógicos? En primer lugar, tenemos que evitar tanto la tendencia entusiasta a identificarnos siempre con la mentalidad dominante del momento como la inclinación, igualmente vigorosa, a oponernos a la misma. Hay que huir también del confort que proporciona el asentimiento gregario con las ideas de los míos, como alejarse igualmente de la tendencia al protagonismo narcisista del pedagogo, educador o profesor díscolo que todo le parece mal por antiguo o conocido. Para poder evitar estos errores es 
necesario que en Pedagogía no miremos ni a derecha ni a izquierda, ni arriba ni abajo, ni a los que están a mi lado o lejos, sino empezar a creer profundamente en la posibilidad de alcanzar algunas verdades, así como a cultivar la virtud intelectual de aceptar y reconocer, además, con admiración y agradecimiento, los mejores argumentos vengan de donde vengan.

En segundo lugar, contra la politización de la educación debemos hacer valer los principios pedagógicos básicos. La educación es un saber práctico pero la Pedagogía se la juega, sobre todo, en la fuerza argumental de las verdades o categorías conceptuales que defendemos. En educación la clave es la atención concreta a las circunstancias, pero debemos insistir que esto no significa que el marco teórico de la Pedagogía sea indiferente en la educación y que no puedan, por tanto, establecerse diferencias entre diversas interpretaciones teóricas acerca de su mayor o menor veracidad (Gil Cantero y Reyero García, 2014, 2015). Atender correctamente a las circunstancias de una situación educativa significa resaltar una verdad práctica que es tal porque se corresponde, se sepa ver o no, con una verdad teórica o premisa mayor que la sostiene y mantiene en la aplicación concreta que sea del caso (Gil Cantero, 2011). Para ello, tenemos que tener la convicción de que hay mejores argumentos que otros y que mejor significa más verdadero, más ajustado a la realidad. Como ha sentenciado el profesor Reyero (2017), desde la traición agustiniana, «es posible dudar de la verdad en las humanidades, pero no me he encontrado con nadie que haya dudado de que existe la mentira, que es una curiosa forma de demostrar que existe lo verdadero".

Por último, quisiera indicar que no estoy tratando de suprimir el debate político pues es justo reconocer que hay múltiples opciones en los temas educativos sujetos a discusión. Pero creo que el saber pedagógico adquiriría más relevancia y consideración social si además de sumarse al espacio de discusión, contribuyese, como todo saber riguroso, a acortarlo, mostrando lo que hoy conocemos como cierto. Si el reconocimiento de los derechos humanos y de la democracia no ha suprimido, por supuesto, el espacio de discusión política pero sí lo ha acortado en unas cuantas certezas ¿por qué no íbamos a lograr lo mismo en el ámbito pedagógico?

\section{RAZONES GNOSEOLÓGICAS}

Es muy conocida la anécdota de Platón contada por Diógenes Laercio (IV, 4): "A uno que quería estudiar con él sin saber ni música ni geometría ni astronomía, Platón le dijo: "Vete, pues no tienes los asideros de la filosofía"». Esta es, para algunos, una de las causas por la que la literatura antipedagógica nos quiere también echar de la academia: ¿Cuáles son los asideros de la Pedagogía? ¿Dónde agarramos a la Pedagogía?

En efecto, como es sabido, una de las críticas habituales contra la Pedagogía, con más extensión y aun tono descalificador, es la relación que los pedagogos mantenemos con los contenidos de los saberes culturales. Reuter (2017) señalaba 
en un número de Cahiers pédagogiques, dedicado al debate antipedagógico, con sus antídotos numerados contra los males de la Pedagogía, que "en términos de métodos de enseñanza, sería mejor centrarse en el sentido común que en el humo de las teorías de las ciencias de la educación (Antídoto, n. ${ }^{\circ} 19$ )». En el contexto sudamericano, tenemos también muchos ejemplos. En un libro subtitulado Para un manifiesto antipedagógico se afirma que «no hay una pedagogía capaz de enseñar una ciencia", y que las ciencias más simples teóricamente son las que más recurren a la Pedagogía (Sanchez-Parga, 2003, 23). En el ámbito portugués-brasileño, en un artículo titulado -cómo no- "Antipedagogismo", se señala con cierta condescendencia que la "práctica pedagógica está impregnada por una insostenible ligereza" (Santoro Franco, 2015, 108).

En realidad, ya Hegel, que atribuía a Kant esta confusión, consideraba que hemos llegado a la "obsesión moderna, especialmente de la Pedagogía, (de que) no se ha de instruir tanto en el contenido de la filosofía, cuanto se ha de procurar aprender a filosofar sin contenido" (Hegel, 1991, 139; cursiva en el original). Ahora bien, no cabe duda de que la referencia más conocida es la de Arendt: «Bajo la influencia de la psicología moderna y de los dogmas del pragmatismo, la pedagogía se desarrolló, en general, como una ciencia de la enseñanza, de tal manera que llegó a emanciparse por completo de la materia concreta que se va a transmitir» (1996, 193-194).

Como en el apartado anterior y siguiendo el objetivo principal de este artículo vamos a analizar de qué modo y por qué la Pedagogía tiene el riesgo cierto de caer en el error señalado y cómo evitarlo.

Como es sabido, en nuestro contexto, uno de los argumentos más extendidos para explicar la peculiaridad de la perspectiva pedagógica estriba en afirmar, como hizo en su día acertadamente el profesor Touriñán (1987, 26 y ss.), de que, con un solo tema, por ejemplo, de historia se pueden lograr todos los objetivos educativos. Me parece que, tal y como se ha terminado desarrollando esta idea por parte de algunos, deberíamos haber añadido también que sin el resto de los temas de historia no se alcanzan realmente los objetivos educativos. Es decir, que sin saberte esos temas no estás realmente educado.

Además, se está extendiendo la idea equivocada de que el conocimiento, desde un punto de vista cuantitativo, puede dificultar la perspectiva pedagógica tanto en quien enseña como en quien aprende. Esto es, que se puede ser mejor profesor cuanto menos se sabe (Rancière, 2003, 20, 9,12), o que para acentuar la educación no es necesario acentuar el saber - «aprender a desaprender»- (Michéa, 2002, 13-14). Ya Revel nos advertía de que se estaba empezando a extender la idea, para disminuir el fracaso escolar, de que "la escuela debe dejar de transmitir conocimientos para convertirse en una especie de falansterio "de convivencia"” (1989, 183). Otra versión más actual del mismo problema lo ha planteado Biesta al señalar que

El punto principal de la discordia parece ser la idea de que la enseñanza es en última instancia una forma de control en la que los estudiantes son tratados como 
objetos y no como sujetos. Dado que la educación, a diferencia del adoctrinamiento, tiene un interés en la libertad del estudiante, es decir, en su existencia como sujetos, la conclusión solo puede ser que la enseñanza se interpone en el camino de la realización de esta libertad (Biesta, 2017b, 96).

Dan Levy, profesor y pedagogo en el Kennedy School de Harvard, es uno de los gurús mediáticos de los programas de formación para profesores de secundaria y universidad y tal vez un nuevo Sexto Empírico contemporáneo. Considera Levy que "es obvio que saber mucho no significa saber enseñar... Es incluso al contrario. Yo, cuanto más experto soy en una materia menos cualificado me siento para entender las dificultades por las que pasa alguien que está aprendiendo» (Levy, 2014; cursiva añadida). No es cierto. El aumento del conocimiento o la especialización en un área cultural no es la causa de la incapacidad para percibir las dificultades de aprendizaje de los alumnos, sino, precisamente, la escasa orientación pedagógica de la adquisición de esa especialización. Es como defender de un modo absurdo que el médico tiene más capacidad de ayudar a curar un enfermo cuanto menos sabe de la enfermedad.

Como han mostrado rotundamente diversos trabajos sobre la docencia de física, ciencias naturales y matemáticas, en primaria y secundaria, lo cierto es todo lo contrario (Halim y Mohd, 2002; Montes et al., 2015). La escasez del conocimiento aritmético de los profesores es la variable que más se correlaciona con las dificultades de esta materia en los propios alumnos. Se ha mostrado también que los docentes con bajo dominio de su materia perciben peor los conocimientos previos de sus estudiantes y, por tanto, los errores que estos puedan cometer. Y es que parece obvio que la capacidad de adaptar el contenido cultural a secuencias explicativas diferentes, según las particulares dificultades de aprendizaje de los alumnos, siempre va a depender de la capacidad que tenga el docente de manejar todos los vericuetos de ese mismo contenido cultural.

Ha sido un error de cierta Pedagogía desprestigiar la perspectiva cuantitativa del aprendizaje tanto en el que enseña como en el que se educa. Cuando se critica el exceso de instrucción sin educación la culpa no es de la instrucción, del mismo modo que cuando se critica el exceso de medicación sin curación la culpa no es de las medicinas. Quiero mantener así la tesis de que la mirada pedagógica, y aun nuestro fundamentante herbartiano círculo visual, podría mejorar en la medida en que se incrementara, por parte de los pedagogos, el conocimiento de las áreas culturales. Se hace más y mejor Pedagogía cuantas más cosas se saben. Y esto es así porque, como nos ha enseñado Ricoeur $(1988,321)$, «el saber no es lo que pienso, sino aquello mediante lo cual pienso". Hay que ayudar a educar, sí, pero sin dejar de llenar las cabezas porque lo que puede impedir la educación no es que estén las cabezas llenas, sino la orientación equivocada de lo que se sabe.

Creo que la principal explicación de cuestionar el interés educativo que puede proporcionar un enfoque cuantitativo del aprendizaje se encuentra en la predominancia abusiva del psicologismo constructivista. En efecto, pocas cosas nos han hecho más daño a los pedagogos que mantener la identificación entre 
comprensión del objeto y comprensión del sujeto. Los requisitos para comprender algo son exigencias de ese algo, no solo de la mente que trata de comprenderlo. A esta lo único que le cabe es adaptarse, si puede, a esas exigencias, no construirlas. Tampoco cabe que ese algo sea el que se adapte a nuestras capacidades sin que, al mismo tiempo, reconozcamos que, entonces, ya no es el algo inicial que teníamos. Comprender algo no es comprender ese algo en el modo de comprensión del otro, sino comprenderlo en sí mismo, en su propio sentido, en lo que es. La idea dominante hoy, por el contrario, en relación con el conocimiento de la realidad, es que lo importante, lo preeminente de esa relación, es la apreciación emocional del yo sobre esa realidad con lo que se termina formando a ese yo en la afirmación voluntariosa de sus quereres y odios, en vez de un yo disciplinado en desarrollar las capacidades intelectuales necesarias para lograr un saber riguroso de la realidad. Como nos han recordado Masschelein y Simons, "la responsabilidad pedagógica no reside en apuntar directamente al (a las necesidades del) niño o al estudiante, sino a las cosas, y a la relación de uno mismo con ellas, es decir, a la relación que el profesor, en tanto pedagogo, mantiene con esas cosas» $(2014,47)$.

Uno de los autores más aclamados en la Pedagogía mundial y muy conocido en nuestro ámbito por algunas traducciones es el pedagogo holandés Max van Manen. Sus libros son una auténtica delicia para experimentar, casi tocar, a través de los diferentes casos que va tratando, el núcleo fundamental del momento o tacto pedagógico. Sin embargo, ha favorecido esa desatención a la realidad que provoca quedarse mirando -y hasta admirando- el dedo que apunta y no a lo que se apunta. Toda su obra se basa en la idea de que "la esencia de la pedagogía es tener una respuesta en el trato con el niño en cada situación específica. La pregunta "¿Qué hacer?" no deriva directamente de los "hechos". Por ejemplo, la observación de que "estos alumnos no se saben las tablas de multiplicar", no es en sí misma suficiente para que el profesor sepa cómo actuar durante la siguiente clase de matemáticas» (van Manen, 1998, 60). En fin, yo creo que la observación de que los alumnos no se saben las tablas de multiplicar es de facto lo más importante para saber cómo tengo que actuar. En otro momento relata el siguiente caso: "Una madre piensa que su hijo John, de siete años, la ha estado cogiendo dinero del monedero. Está bastante segura de que fue él quien lo cogió, y además tiene un serio reparo moral contra el hecho de robar. Pero esto no le es de gran ayuda a la hora de saber cómo tiene que actuar con John» (op. cit., 52). En fin, yo creo, de nuevo, que tener el reparo moral contra el hecho de robar es de facto lo más importante a la hora de saber cómo tengo que actuar con John.

Me parece que lo que necesitamos, en primer lugar, en Pedagogía y para hacer Pedagogía, son profesores que se escandalicen por tener alumnos que no se sepan las tablas de multiplicar, y padres que repudien moralmente el acto de robar, pues puede ocurrir -y es de lo que nos acusa el antipedagogismo- que, para educar, dejemos de dar importancia a saberse las tablas de multiplicar y a robar. 


\section{RAZONES NORMATIVAS}

Al final de Amor y Pedagogía, Apolodoro, desesperado, se pregunta "¿en qué estaría pensando mi padre cuando me engendró? En la pedagogía, sí, en la pedagogía; ¡me lo dice la conciencia! Y así he salido [...]». Y dirigiéndose a su amada Clara la exhorta, "Pudiste redimir de la pedagogía a un hombre... Que hagas hombres, hombres de carne y hueso, en amor y no en pedagogía!» (Unamuno, 1902, 199 y 198).

Otra de las razones que explican la desacreditación del pensamiento pedagógico se encuentra en nuestra tendencia a identificar la educación con la vida, esto es, con las experiencias particulares, los acontecimientos vitales o la felicidad. No es raro que algún alumno, sobre todo, de cursos avanzados, te advierta airadamente que "si planificas la educación ya no es educación". Por eso, un frente abierto permanentemente de la literatura antipedagógica es lo que Isambert-Jamati (1985, 61) ha denominado argumentos "pedantes y pomposos" de los pedagogos pues nos gusta proclamar -como el cartel que hay al entrar en mi Facultad- de que «educar es vivir".

Si bien, como es sabido, se puede rastrear históricamente el origen de esta identificación vamos a ver, sin embargo, algunos ejemplos recientes. "La pedagogía de la alteridad es una pedagogía testimonial, no técnica, ni planificada [...] En la relación educativa (por tanto, ética) no tiene fácil acomodo la explicación porque en aquella nada es definitivo, todo es contingente, fluido y cambiante, como el mismo ser humano». (Ortega, 2016, 259; cursivas en el original).

Biesta (2017a), basándose también en Levinas y en cierta teología existencialista, defiende una "pedagogía del acontecimiento" - por cierto, iniciada hace tiempo y bien desarrollada entre nosotros por el profesor Bárcena (2012, 2015)- puesto que, afirma el pedagogo holandés, si "la esencia de cualquier labor educativa (reside) en el surgimiento de la subjetividad humana [...] En esta, la subjetividad no se entiende como una esencia sino como un acontecimiento, y de este modo, como algo que solo puede plasmarse en términos existenciales y, por tanto, frágiles» (Biesta, 2017a, 23; vid. Buxarrais y Burguet, 2016).

Una consecuencia teórica y práctica de todas estas propuestas es la paulatina tendencia a disolver los marcos normativos de la educación. Por ejemplo, los profesores Pallarés y Chiva consideran que «los paradigmas basados en entender que toda actividad práctica como la educación, deben estar subordinados a teorías ya no son aceptados por la pedagogía" (2017, 73-74), entre otras razones, porque "la época del mero análisis, de la especulación y del esencialismo pedagógico ya no tiene sentido» (40; vid. 42 y 82). "Si la respuesta (a esto) es afirmativa, la pedagogía postmoderna podría inscribirse de algún modo en lo que se consideró la necesaria negación de la teoría educativa de la Modernidad para poder elaborar una nueva base teórica» (Laudo, 2011, 63). Esta tendencia a cuestionar la normatividad de la Pedagogía la vamos a encontrar también en los argumentos de fondo de Biesta cuando señala: "La búsqueda de la certidumbre [...] siempre nos trae problemas (porque) nos aleja de comprometernos con la vida misma -nos aleja de las cosas 
que tenemos justo delante de nuestros ojos-, de las cosas que realmente importan y que requieren nuestra atención, aquí y ahora” (2017a, 36).

A mi modo de ver, puede haber cierta contradicción de fondo en todos estos argumentos. Si todo es provisional, si la educación más profunda no puede ser de algún modo planificada, suscitada o provocada, si todo es contingente y fluido y cambiante e imprevisible, ¿cómo podemos hacer Pedagogía? Si las acciones prácticas, las verdades prácticas concretas, no derivan de verdades teóricas previas, de ciertos principios, todo lo provisionales que se quieran, ¿por qué he de esperar que espontáneamente me sienta obligado ante el rostro del otro? Dicho de otro modo, para poder pensar y actuar pedagógicamente es necesario aceptar un deber o una medida distinta a las circunstancias concretas en las que nos encontramos, porque lo que nos educa es, precisamente, hacer nuestros esos deberes o medidas para poder cambiar así nuestras circunstancias. "De modo que sin intención normativa no hay Pedagogía» (Trilla, 2005, 294).

Las experiencias por sí mismas no marcan los efectos educativos. Ayudar a educar a alguien estriba, precisamente, en ayudarle a cuestionarse críticamente los efectos educativos de sus propias experiencias, tanto de las imprevistas como de las buscadas. Vivo en mis circunstancias, pero no soy solo mis circunstancias ni estas son la medida de mí mismo, ni de mis posibilidades futuras. El pensamiento pedagógico debe ayudar al sujeto no a ensimismarse en sus propias experiencias, sino a aspirar a tener experiencias que reflejen lo mejor de entre lo más común, esto es, de lo más universal de la cultura de lo humano.

Yo tengo una idea extraña, muy alejada de lo que se escucha habitualmente sobre este tema, idea comprobada muchas veces, y es que lo que es bueno para todos, y universalmente humano, es precisamente aquello que parece haber sido escrito para cada uno; al contrario de aquello que pretende dirigirse a mí, niño u hombre, y ponerse a mi nivel, que está siempre al margen, y a menudo por debajo, de mis intereses (Alain, 2002, 71).

Por último, no hay ninguna contradicción entre el fluir dinámico y cambiante de la vida y la búsqueda de certezas. Todo lo contrario: las experiencias vividas siempre buscan razones por inseguras, temporales o erradas que sean. Y es que no se vive más y mejor por carecer de certezas, simplemente puedes vivirlo todo sin la sensación de haber cometido error, culpa o contradicción alguna. Y todavía hay más porque en educación se trata, en rigor, de saber ver la diferencia entre los "acontecimientos (que) son palabras que hay que descifrar [...] y «la Tradición [...] (que) son ante todo las palabras que nos descifran a nosotros» (Haddjadi, 2016, 32).

Ahora bien, es cierto que la educación «no deja de ser un misterioso golpe repentino en la interioridad por el que el sujeto empieza a querer verse reflejado de otro modo en el espejo de su futuro" (Gil Cantero, 2003, 128). Y es verdad que nadie puede elegir ese momento. Ni podemos vivirlo por otro. Tampoco cabe buscarlo en una sola dirección. Y aun menos conocemos la causa final. Pero, precisamente, la Pedagogía se cultiva cuando se tiene la convicción de que se puede 
ayudar a un sujeto a acercarse a las mejores condiciones para poder vivir ese misterio desde las acciones que se le proponen porque, a su vez -y esto es esencialse tiene el convencimiento de que existe una línea de correspondencia entre esas acciones y experiencias y los efectos educativos que, como surcos, inciden en su mayor o menor desarrollo humano.

Creo que la literatura antipedagógica tiene muchas posibilidades de seguir atacándonos si solo nos quedamos en el misterio de la vida, la felicidad, las experiencias particulares o los fines últimos de la existencia. Todo esto, es cierto, es lo más importante, pero no es Pedagogía. Como nos ha recordado el profesor Touriñán, "la finalidad de la educación, es que el educando adquiera conocimientos, actitudes y destrezas-habilidades-hábitos que lo capacitan, desde cada actividad interna (pensar, sentir, querer, operar, proyectar y crear) y externa (juego, trabajo, estudio, profesión, investigación y relación) para decidir y realizar sus proyectos, dando respuesta de acuerdo con las oportunidades a las exigencias que se plantean en cada situación» $(2015,60$; cursiva añadida).

Pienso que hay dos tendencias culturales actuales que pueden ayudarnos a explicar las razones de este alejamiento de la Pedagogía de las tradicionales perspectivas planificadoras, intencionales y normativas. Por un lado, como ha mostrado Barrio (2008), para muchos la Pedagogía no puede ser concebida como un saber que pueda juzgar y aun limitar la libertad. En efecto, esta tendencia ya la adivinó hace tiempo Ricoeur cuando dejó escrito: "En nuestros días, vemos que la idea misma de una mediación institucional de la libertad retrocede en los pensamientos y deseos. Nuestros contemporáneos están cada vez más tentados por la idea de una libertad salvaje, fuera de las instituciones, mientras que toda institución les parece de naturaleza esencialmente coercitiva y represiva" (Ricoeur, 2001, 235). Creo que el ansia ilimitada de libertad, propia de la condición humana, participa de la idea de educación, convirtiendo a esta erróneamente, en ocasiones, en un proceso no de aprendizaje de lo que de humano tienen los limites, sino, precisamente, para algunos, en un aprendizaje de lo que de deshumano tiene ponerse límites. Hay así una tendencia a desacreditar a la Pedagogía como saber normativo capaz de elaborar juicios educativos sobre el ejercicio de la libertad particular de cada uno.

Otra tendencia cultural que casa muy bien con la anterior es el ansia ilimitada de individualidad. Como ha explicado Gomá: "La conciencia romántica quiso convencernos de que la esencia de nuestra individualidad estriba en la extravagancia [...]: soy yo mismo sólo cuando soy diferente o especial. Pero cuando, por juzgarse cada uno distinto de los demás, la universalidad humana está por principio excluida, ninguna ejemplaridad cabe» (Gomá, 2014, 142). Ninguna normatividad cabe, diríamos nosotros. Pues bien, creo que, como en el caso anterior, el ansia ilimitada de individualidad, propia de la condición humana, participa de la idea de educación, convirtiendo a esta erróneamente, en ocasiones, en un proceso no de aprendizaje de lo común humano sino, precisamente, para algunos, en un aprendizaje para ser diferente y distinto. Hay así, de nuevo, una tendencia a 
desacreditar a la Pedagogía como saber normativo capaz de elaborar juicios educativos universales.

No es muy difícil ver proyectada en la Pedagogía actual esta ansia cultural ilimitada de libertad y de diferenciación y aun extravagancia. En efecto, hay que reconocer que los pedagogos somos un gremio que, en general, nos deslumbran las propuestas de teorías y prácticas novedosas, y aun mejor rompedoras, extrañas, chocantes, y, por supuesto, las preferimos acompañadas de adjetivos llamativos: tenemos así Pedagogías "lentas», "inversas», "fluidas», "libres», "rizomáticas", "cruzadas", "de la metamorfosis", "regenerativas», "performativas» y hasta asombrosamente «invisibles». Hace poco la Fundación Telefónica ha publicado en su página web, con acceso libre, siete largos textos sobre Escuelas creativas basadas en la metodología innovadora del cocinero Adrià, quien en el preámbulo señala: "Trasladar el método de elBulli a la educación ha sido una aventura enriquecedora y sorprendente [...] "Ferran", me decían, "eso nunca se ha hecho así". Y llevaban razón. [...] ¿A quién se le había ocurrido servir humo? [...] Y yo me pregunto: ¿no se podría empezar esa revolución en nuestra educación, comenzar a hacer las cosas como nunca se hacían?» (Adrià, 2017). Desde esta perspectiva no nos ha de extrañar que otra pedagoga de fortuna, muy solicitada en todo tipo de medios y foros, María Acaso, enemiga de lo que denomina "Pedagogía tóxica», razone sin ruborizarse: "Llevar una sandía a clase es un acto de subversión, hace que el aula explote" (Acaso, 2017). En fin, con estos amigos del gremio, ¿quién necesita más enemigos?

\section{CONCLUSIÓN}

El trabajo de la Pedagogía es especialmente complejo. Su tarea es muy peculiar pues ha de centrarse en ayudar a los sujetos a educarse, a lograr que florezca una identidad personal sujeta a criterios intelectuales y éticos. Como ha señalado el profesor Ibáñez-Martín, "la pedagogía está llamada a encontrar respuestas racionales a cuestiones esenciales», además, "la pluralidad de requerimientos que en la actualidad se abaten sobre la educación [...] convierten al saber pedagógico en una empresa erizada de dificultades» (Ibáñez-Martín, 2017, 63 y 64).

Así mismo, debemos reconocer también que la Pedagogía es un saber en muchas ocasiones molesto, irritante, inoportuno, enojoso, exasperante porque tenemos el atrevimiento de sugerir, entre otras cuestiones, los mejores modos y fines de favorecer el desarrollo humano, precisamente poniendo límites donde nadie quiere oírlos y mucho menos tenerlos. Esto, hay que reconocer una vez más, levanta pocas simpatías pues siempre nos pueden reprochar: "quién eres tú para decirme cómo debo ser yo». No nos falta tampoco a los pedagogos un cierto espíritu soñador, permanentemente inconformista, poco complaciente con las teorías y prácticas educativas dominantes, en fin, como vimos antes, proclive a todo tipo de cambios y aun de revoluciones en la educación. Es conocida la simpática anécdota de un matrimonio con hijos pequeños, con escasas posibilidades de poder salir, que por fin consiguen responder a una invitación de una cena en casa de unos 
amigos. Ya de vuelta, en el coche, se lamentan entre ellos de la mala suerte que han tenido pues para una vez que pueden salir les toca al lado de... ¡horror! sí, de un pedagogo: alguien que en un par de horas que dura la velada quiere cambiar el mundo.

En fin, está claro que no somos un gremio que de entrada suscite simpatía, salvo que digamos lo que los demás quieren oír, que es, precisamente, lo que hace la literatura antipedagógica. Y, tal vez, además, prime hoy en la sociedad «una especie de desconfianza, duda, escepticismo sobre el papel (de) la educación» (García del Dujo, 2014, 169). Ahora bien, las peculiaridades y dificultades que caracterizan a la Pedagogía por su objeto y enfoque de estudio no justifican los ataques desmedidos contra la misma y, mucho menos, los discursos que, como hemos visto, buscan su descrédito y aun desaparición. Contra estos lo mejor es el silencio. Solo debemos atender a la literatura antipedagógica que fundamenta, de algún modo, sus propuestas, pues siempre vamos a encontrar nuevos sofistas, disfrazados de pedagogos, para quienes lo importante no es ni decir la verdad ni ayudar a nadie sino convencer a alguien de sus ocurrencias.

Lo que sí está en nuestras manos -y esta ha sido la intención principal de este artículo- es evitar, en la medida de lo posible, los errores a los que nos pueden llevar no atender suficientemente a determinados riesgos del pensamiento pedagógico. Riesgos que, como hemos visto, se concentran en la actualidad en querer arrastrar a la Pedagogía a un marco simplista y cerrado de razonamientos políticamente polarizados, a contraponer el conocimiento cultural a la mirada educativa y, por último, a alejarnos de nuestras obligaciones profesionales normativas.

Para finalizar, me gustaría proponer un deseo y un horizonte de trabajo pedagógico. El deseo lo he encontrado expresado en el libro de Masschelein y Simons cuando reclaman uun enérgico llamamiento a todos los pedagogos para que se levanten (otra vez) y se hagan oír» $(2014,77)$. En efecto, tenemos que seguir haciéndonos notar en cualquier lugar, también en las cenas con los amigos, sin complejos, sin agachar la mirada, sin bajar el tono de voz, sin pedir perdón por las tonterías pedagógicas que otros puedan decir, aunque debemos reconocerlas y atacarlas. Y si alguno no se atreve, o se siente ya cansado, quiero proponerle un antídoto: si la literatura antipedagógica ha sido capaz de dejar por escrito que Pestalozzi, Kant o Herbart eran «alquimistas pedagógicos» que padecían de «alucinaciones extrañas, engañosas, y espejismos intelectuales» (Rivera, 1910, tomo II, 185), poco importa ya lo que puedan decir de nosotros.

El horizonte intelectual del trabajo pedagógico me lo ha sugerido el profesor Reboul, quien al reseñar el libro de Milner -antes mencionado- le plantea la siguiente observación: «Sí, nuestra escuela siempre tiene necesidad de maestros realmente competentes en sus disciplinas y amándolas lo suficiente para saberlas comunicar. Pero un maestro que rechazase ser pedagogo, que rechazase hacerse cargo de sus alumnos con sus problemas o sus dramas sería acaso del todo honesto, ¿sería solamente un "maestro”?» (Reboul, 1985, 73). 
Esta observación me parece relevante. En efecto, los pedagogos, la Pedagogía es despreciada, en ocasiones, en el mismo punto en que se recela del misericordioso. No nos debe importar mientras sigamos recordando a la sociedad, entre otras cuestiones, la necesidad de cuidar del último que ocupa el último lugar en la última fila del aula, del patio, del barrio, de su familia, de la sociedad. Ahora bien, para lograr eso, creo que hemos de centrarnos en desarrollar una Pedagogía sujeta a la realidad, a lo que las cosas son, capaz de sugerir sin complejos los órdenes de sentido que se nos van desvelando y que mejor pueden desarrollar la condición humana. Una Pedagogía, en fin, que acentúa y fundamenta lo teórico, la realidad, en su ser educación, para mejorar así los motivos que sostienen las diferentes orientaciones prácticas.

\section{REFERENCIAS BIBLIOGRÁFICAS}

Acaso, M. (2017) Profesoras contra la pedagogía tóxica. El País, 13 de febrero. Consultado el 8 de abril de 2018. https://elpais.com/economia/2017/02/07/actualidad/1486485679_572946.html.

AdriÀ, F. (2017) Preámbulo, en AA. VV. Escuelas Creativas. Un viaje hacia el cambio educativo. Madrid, Fundación Telefónica. Consultado el 8 de abril de 2018. https://www.fundaciontelefonica.com/arte_cultura/publicaciones-listado/pagina-item-publicaciones/ itempubli/612/.

ARENDT, H. (1996) La crisis de la educación, en AREndt, H., Entre el Pasado y el Futuro. Ocho ejercicios sobre reflexión política. Barcelona, Península, 185-208.

Alain (2002) Charlas sobre educación. Pedagogía infantil. Barcelona, Losada.

Ballester, L. y Colom, A. J. (2012) Epistemología de las ciencias sociales y de la educación. Valencia, Tirant.

BÁrCEnA, F. (2012) Una pedagogía de la presencia. Crítica filosófica de la impostura pedagógica. Teoría de la Educación. Revista Interuniversitaria, 24, 25-57. Consultado el 8 de abril de 2018. http://revistas.usal.es/index.php/1130-3743/article/view/10354.

Bárcena, F. y Mèlich, J. C. (2015) La educación como acontecimiento ético. Natalidad, narración y hospitalidad. Barcelona, Paidós.

BARRIO, J. M. (2008) Educación y verdad. Teoría de la Educación. Revista Interuniversitaria, 20, 83-99. Consultado el 8 de abril de 2018. http://revistas.usal.es/index.php/1130-3743/ article/viewFile/985/1083.

BentoliLA, A. (2017) L'École contre la barbarie. Paris, First.

Biesta, G. J. J. (2017a) El bello riesgo de educar. Cada acto educativo es singular y abierto a lo imprevisto. Madrid, SM.

Biesta, G. J. J. (2017b) The reciscovery of Teaching. London, Routledge.

Buxarrais, M. ${ }^{a}$ R. y Burguet, M. (coords.) (2016) Aprender a ser. Por una pedagogía de la interioridad. Barcelona, Graó.

CARbonell, J. (2017) Hay vida e innovación más allá del neoliberalismo. Blog Pedagogías del siglo XXI. El Diario de la Educación, 14 de junio. Consultado el 8 de abril de 2018. http://eldiariodelaeducacion.com/pedagogiasxxi/2017/06/14/ hay-vida-e-innovacion-mas-alla-del-neoliberalismo/.

CARrera, P. y LuQue, E. (2016) Nos quieren más tontos. La escuela según la economía neoliberal. Barcelona, El Viejo Topo. 
Chambat, G. (2017) Esquisse d'une bibliographie de "l'antipédagogisme»: 19782016. Consultado el 8 de abril de 2018. https://www.questionsdeclasses.org/ reac/?Esquisse-d-une-bibliographie-de-l-antipedagogisme-1978-2016.

Decell, L. (2017a) Les 10 "avantages» de l'antipédagogisme. 2 de enero. Consultado el 8 de abril de 2018. http://education.blog.lemonde.fr/2017/01/02/ les-10-avantages-de-lantipedagogisme/.

Decell, L. (2017b) L'antipédagogisme, ce vêtement universel. 9 de enero. Consultado el 8 de abril de 2018. http://education.blog.lemonde.fr/2017/01/09/ lantipedagogisme-ce-vetement-universel/.

Dewey, J. (2010) Experiencia y educación. Madrid, Biblioteca Nueva. Traducción: Lorenzo Luzuriaga. Edición y estudio introductorio: Javier Sáenz Obregó.

Diógenes LAeRcio (1792) Los diez libros de Diógenes Laercio sobre las vidas, opiniones y sentencias de los filósofos más ilustres. Madrid, Imprenta Real. Traducción y notas de Josef Ortiz y Sanz. Consultado el 8 de abril de 2018. http://www.cervantesvirtual.com/ obra/los-diez-libros-de-diogenes-laercio-sobre-las-vidas-opiniones-y-sentencias-de-losfilosofos-mas-ilustres/.

Finkielkraut, A. (1991) Que pensez vous des Iufm? Le Point, (995), 12 de octubre.

Finkielkraut, A. (2002) Una voz viene de la otra orilla. Buenos Aires, Paidós.

FInKIELKRAUT, A. (2014) La Identidad desdichada. Madrid, Alianza.

FERNÁNDEZ LIRIA, C. (2015) ¿Qué programa queremos para Educación? Cuartopoder, 8 de noviembre. Consultado el 8 de abril de 2018. https://www.cuartopoder.es/ideas/ opinion/2015/11/08/que-programa-queremos-para-educacion/.

FERNÁNDEZ LiRIA, C.; GARCía FERNÁNDEZ, O. y GALINDO FERNÁNDEZ, E. (2017) Escuela o barbarie. Entre el neoliberalismo salvaje y el delirio de la izquierda. Madrid, Akal.

ForestieR, Y. (2017) Les savoirs contre la pédagogie? Interroger la symétrie des querelles sur l'école. Mots. Les langages du politique, 13, 75-92.

García Carrasco, J. (1983) La ciencia de la educación. Pedagogos, ¿para qué? Madrid, Santillana.

García Carrasco, J. y García del Dujo, Á. (2001) Teoría de la Educación II. Procesos primarios de formación del pensamiento y la acción. Salamanca, Ediciones Universidad de Salamanca.

García Del Dujo, Á. (2014) Viaje autoetnográfico por (la vida institucional de) la Teoría de la Educación. Notas de campo, en RABAZAS, T. (coord.) El conocimiento teórico de la educación en España. Evolución y consolidación. Madrid, Síntesis, 149-170.

Gil Cantero, F. (2003) La filosofía de la educación como teoría ética de la formación humana. Revista Española de Pedagogía, 61 (204), 115-130. Consultado el 8 de abril de 2018. https://revistadepedagogia.org/wp-content/uploads/2007/06/224-06.pdf.

Gil CANTERo, F. (2011) «Educación con teoría». Revisión pedagógica de las relaciones entre la teoría y la práctica educativa. Teoría de la Educación. Revista Interuniversitaria, 23 (1), 19-43. Consultado el 8 de abril de 2018. https://gredos.usal.es/jspui/bitstream/103 66/121615/1/\%C2\%ABEducacion_con_teoria\%C2\%BB_Revision_pedagogi.pdf.

Gil CANTERo, F. y Reyero García, D. (2014) La prioridad de la filosofía de la educación sobre las disciplinas empíricas en la investigación educativa. Revista Española de Pedagogía, 72 (258), 263-280. Consultado el 8 de abril de 2018. http://rd.unir.net/sisi/research/ resultados/Fernando\%20Gil\%20Cantero\%20y\%20David\%20Reyero.pdf.

Gil Cantero, F. y Reyero García, D. (2015) Lo real, lo actual, lo empírico... y la esperanza en lo posible. Sobre regularidades y sentidos en educación. Revista Española de 
Pedagogía, 73 (262), 519-526. Consultado el 8 de abril de 2018. https://revistadepedagogia.org/wp-content/uploads/2015/11/Lo-real-lo-actual-lo-emp\%C3\%ADrico\%C5\%A0-yla-esperanza-en-lo-posible.-Sobre-regularidades-y-sentidos-en-educaci\%C3\%B3n.pdf.

GOMÁ, J. (2014) Razón: portería. Barcelona, Galaxia Gutenberg.

HADJADI, F. (2016) La suerte de haber nacido en nuestro tiempo. Madrid, Rialp.

Halim, L. y MoHD, M. S. (2002) Science trainee teachers' pedagogical content knowledge and its influence on physics. Teaching Research in Science \& Technological Education, 20 (2), 215-225.

Hegel, G. W. F. (1991) Escritos pedagógicos. México, FCE. Traducción: Arsenio Ginzo.

Herrán, A. de la (coord.) (2012) Apuntes de pedagogía: la figura del pedagogo boy. Madrid, Colegio Profesional de la Educación.

IBÁÑEZ-MARTín, J. A. (2017) Horizontes para los educadores. Las profesiones educativas y la promoción de la plenitud humana. Madrid, Dykinson.

ISAMBERT-JAMATI, V. (1985) Les primaires, ces «incapables prétentieux». Revue française de pédagogie, 73, 57-65.

JimÉnez Losantos, F. (2014) Es la mañana de Federico. EsRadio, 20 de marzo.

KAHN, P. (2006) La critique du "pédagogisme» ou l'invention du discours de l'autre. Les Sciences de l'éducation - Pour l'Ére nouvelle, 39 (4), 81-96. Consultado el 8 de abril de 2018. https://www.cairn.info/revue-les-sciences-de-l-education-pour-l-ere-nouvelle2006-4-page-81.html.

LAUDO, X. (2011) La hipótesis de la pedagogía postmoderna. Educación, verdad y relativismo. Teoría de la Educación. Revista Interuniversitaria, 23 (2), 45-68. Consultado el 8 de abril de 2018. https://gredos.usal.es/jspui/bitstream/10366/131018/1/La_hipotesis_de_la_pedagogia_postmoderna.pdf.

LEVY, D. (2014) Enseñar a enseñar. El Paîs, 8 de diciembre. Consultado el 8 de abril de 2018. https://politica.elpais.com/politica/2014/12/04/actualidad/1417717866_624002.html.

LOQUillo (2011) Political Incorrectness, en LOQUiLlo Su nombre era el de todas las mujeres. Madrid, Warner Music. Consultado el 8 de abril de 2018. http://www.loquillo.com/ portfolio/su-nombre-era-el-de-todas-las-mujeres/.

Manifiesto de maestros y PROFESOREs (2010) Por un sistema educativo libre, eficaz e independiente. Promovido por David López Sandoval. Consultado el 8 de abril de 2018. https://deseducativos.wordpress.com/manifiesto-deseducativo/.

Marías, J. (2016) Javier Marías enseña "El Quijote». El Periódico, 21 de junio. Consultado el 8 de abril de 2018. https://www.elperiodico.com/es/ocio-y-cultura/20160621/ javier-marias-el-quijote-wellesley-5219777.

Masschelein, J. y Simons, M. (2014) Defensa de la escuela. Una cuestión pública. Buenos Aires, Miño y Dávila.

Massó, X. (2013) El fracaso escolar. Para Todos La 2 Debate. 25 de enero. Consultado el 8 de abril de 2018. https://www.youtube.com/watch?v=M_EsJoDDp0c.

Meirieu, P. (2000) Une odieuse chasse au pédagogue. Le Monde, 12 de mayo. Consultado el 8 de abril de 2018. https://www.meirieu.com/POLEMIQUES/chasse.pdf.

MichÉA, J.-Cl. (2002) La escuela de la ignorancia y sus condiciones modernas. Madrid, Acuarela.

Milner, J.-Cl. (1984) De l'école. Paris, Seuil. Reeditado en 2009: Paris, Verdier.

Montes, M. A. et al. (2015) Conocimiento de aritmética de futuros maestros. Debilidades y fortalezas. Revista de Educación, (367), 36-62. Consultado el 8 de abril de 2018. https:// 
www.mecd.gob.es/dctm/revista-de-educacion/articulos367/re367.pdf?documentId=09 01e72b81b771b8.

Moreno Castillo, R. (2016a) La conjura de los ignorantes. De cómo los pedagogos han destruido la enseñanza. Madrid, Pasos Perdidos. (Prólogo: Arcadi Espada).

Muñoz Molina, A. (1997) La historia y el olvido. El País, 9 de noviembre. Consultado el 8 de abril de 2018. https://elpais.com/diario/1997/11/09/opinion/879030003_850215.html.

OAnceA, A. y PRING, R. (2008) The Importance of Being Thorough: On Systematic Accumulations of "What Works» in Education Research. Journal of Philosophy of Education, 42(1), 15-39.

Ortega, P. (2016) La ética de la compasión en la pedagogía de la alteridad. Revista Española de Pedagogía, 74 (264), 243-264. Consultado el 8 de abril de 2018. https://revistadepedagogia.org/wp-content/uploads/2016/04/La-\%C3\%A9tica-de-la-compasi\%C3\%B3nen-la-pedagog\%C3\%ADa-1.pdf.

Pallarés, M. y Chiva, O. (2017) La pedagogía de la presencia. Tecnologías digitales de aprendizaje servicio. Barcelona, UOC.

Pérez-Reverte, A. (2007) Permitidme tutearos, imbéciles. El Semanal, 23 de diciembre. Consultado el 8 de abril de 2018. http://www.perezreverte.com/articulo/patentes-corso/178/ permitidme-tutearos-imbeciles/.

PRADA. J. M. de (2017) Escuela o barbarie. XL Semanal, 19 de junio. Consultado el 8 de abril de 2018. http://www.xlsemanal.com/firmas/20170619/juan-manuel-de-prada-escuelao-barbarie.html.

PRATS, E. (2015) Teorizando en educación. Entre erudición, poesía y opinionitis. Barcelona, UOC.

RANCIÈRE, J. (2003) El maestro ignorante. Cinco lecciones sobre la emancipación intelectual. Barcelona, Laertes.

Reboul, O. (1985) Milner-De l'école. Revue française de pédagogie, vol. 71, 71-73.

REUTER, Y. (2017) La recherche en éducation est-elle aussi inutile que nuisible? Antidote n. ${ }^{\circ}$ 19. Cabiers pédagogiques, abril.

Revel, J.-F. (1989) El conocimiento inútil. Barcelona, Planeta.

REYERo, D. (2017) Adoctrinamiento y educación. El Debate de Hoy, 5 de junio. Consultado el 8 de abril de 2018. https://eldebatedehoy.es/educacion/adoctrinamiento-y-educacion/.

Rivera, J. de (1910) La superstición pedagógica. Tomo I y II. Madrid, Ibérica-Maestre.

Ricoeur, P. (1988) Lo voluntario y lo involuntario, Tomo II. Buenos Aires, Docencia.

Ricoeur, P. (2001) Ensayos de hermenéutica II. Del Texto a la acción. Buenos Aires, FCE.

SÁnchez-Parga, J. (2003) La docencia universitaria. Para un manifiesto antipedagógico. Quito, Abya-Yala.

Santo Guerra, M. A. (2017) Carta abierta a un antipedagogo. La opinión de Málaga, 28 de octubre. Consultado el 8 de abril de 2018. http://mas.laopiniondemalaga.es/blog/ eladarve/2017/10/28/carta-abierta-anti-pedagogo/.

Santoro Franco, M. ${ }^{a}$ A. (2015) Antipedagogismo. Revista de Estudios de Cultura, (2), 99-109. Steiner, G. y Ladjali, C. (2005) Elogio de la transmisión. Madrid, Siruela.

Thoilliez, B. (2015) La Teoría de la Educación en España: diagnóstico, pronóstico y (posible) tratamiento, en RABAZAS, T. (coord.) El conocimiento teórico de la educación en España. Evolución y consolidación. Madrid, Síntesis, 207-223.

Touriñán, J. M. (1987) Teoría de la educación. La educación como objeto de conocimiento. Madrid, Anaya. 
Touriñán, J. M. (2014) Dónde está la educación: actividad común interna y elementos estructurales de la intervención. La Coruña, Netbiblo.

Touriñán, J. M. (2015) Pedagogía mesoaxiológica y concepto de educación. Santiago de Compostela, Andavira.

Trilla, J. (2005) Hacer Pedagogía hoy, en Ruiz Berrio, J. (ed.) Pedagogía y Educación ante el siglo XXI. Madrid, Departamento de Teoría e Historia de la Educación, Universidad Complutense de Madrid, 287-310.

Trilla, J. (2009) Bolonya i la Pedagogia residual. Temps d'Educació, (37), 219-234.

Unamuno, M. de (1902) Amor y pedagogía. Barcelona, Henrich editores.

VAN MANEn, M. (1998) El tacto en la enseñanza. El significado de la sensibilidad pedagógica. Barcelona, Paidós.

Vilanou, C. (2015) Muerte del hombre y muerte de la Pedagogía: de la escatología cristiana al presentismo postmoderno, en CAgnolati, A. y Hernández Huerta, J. L. (coords.) La Pedagogía ante la Muerte: reflexiones e interpretaciones en perspectivas histórica y filosófica. Simposio de Historia de la Educación. Actas. Salamanca, FahrenHouse, 209-212. Consultado el 8 de abril de 2018. www.fahrenhouse.com/omp/index.php/fh/catalog/ view/13/9/53-1. 